\title{
Microstructure Evolution and High-Temperature Compressibility of Modified Two-Step Strain-Induced Melt Activation-Processed Al-Mg-Si Aluminum Alloy
}

\author{
Chia-Wei Lin, Fei-Yi Hung *, Truan-Sheng Lui and Li-Hui Chen \\ Department of Materials Science and Engineering, National Cheng Kung University, Tainan 701, Taiwan; \\ qqkm0526@gmail.com (C.-W.L.); luits@mail.ncku.edu.tw (T.-S.L.); chenlh@mail.ncku.edu.tw (L.-H.C.) \\ * Correspondence: fyhung@mail.ncku.edu.tw; Tel.: +886-6-275-7575 (ext. 31395); Fax: +886-6-234-6290 \\ Academic Editor: Soran Birosca \\ Received: 3 February 2016; Accepted: 10 May 2016; Published: 13 May 2016
}

\begin{abstract}
A two-step strain-induced melt activation (TS-SIMA) process that omits the cold working step of the traditional strain-induced melt activation (SIMA) process is proposed for $6066 \mathrm{Al}-\mathrm{Mg}$-Si alloy to obtain fine, globular, and uniform grains with a short-duration salt bath. The results show that increasing the salt bath temperature and duration leads to a high liquid phase fraction and a high degree of spheroidization. However, an excessive salt bath temperature leads to rapid grain growth and generates melting voids. The initial degree of dynamic recrystallization, which depends on the extrusion ratio, affects the globular grain size. With an increasing extrusion ratio, the dynamic recrystallization becomes more severe and the dynamic recrystallized grain size becomes smaller. It results in the globular grains becomes smaller. The major growth mechanism of globular grains is Ostwald ripening. Furthermore, high-temperature compressibility can be improved by the TS-SIMA process. After a $4 \mathrm{~min}$ salt bath at $620^{\circ} \mathrm{C}$, the high-temperature compression ratio become higher than that of a fully annealed alloy. The results show that the proposed TS-SIMA process has great potential.
\end{abstract}

Keywords: aluminum alloy; strain-induced melting activation (SIMA); semi-solid metal processing; high-temperature compression

\section{Introduction}

6xxx series $\mathrm{Al}$ alloys, a series of precipitation-hardened $\mathrm{Al}$ alloys, are widely used. The present study considers $6066 \mathrm{Al}$ alloy, whose strength is higher than that of the great majority of other alloys in this series due to its $\mathrm{Cu}$ and $\mathrm{Mn}$ addition and excess Si [1,2]. According to previous research, adding $\mathrm{Cu}$ can improve strength and hardness by refining the precipitated phases during artificial aging [3]. Adding Mn enhances corrosion resistance, improves mechanical strength, increases the recrystallization temperature, and inhibits grain growth [4]. Even though adding $\mathrm{Cu}$ and $\mathrm{Mn}$ increases strength, they decrease formability. In order to overcome this problem, the strain-induced melt activation (SIMA) process is used in forming alloys at high temperatures.

The SIMA process is a semi-solid process, in which the materials are manufactured at the temperature of the mushy zone. The finished products have a near-net-shape advantage [5]. Due to its low cost and high stability, the SIMA process is useful. Figure 1a shows the procedure of the traditional SIMA process [6-12]. The steps are: (1) casting, which produces a dendritic structure; (2) hot work, which disintegrates the initial structure; (3) cold work, which introduces strain energy into the alloy; and (4) heat treatment, which makes the material recrystallize and partially melt at the temperature of solid-liquid coexistence. It is defined as a three-step process because casting materials is done via three steps to obtain globular grains. This study proposes an improved SIMA process that has 
two steps after casting. The two major differences between the traditional SIMA process and the proposed two-step SIMA (TS-SIMA) process are: (1) the proposed TS-SIMA process uses severe hot extrusion instead of cold work to introduce a large amount of strain energy; (2) the proposed SIMA process uses a salt bath instead of an air furnace to improve heating uniformity and reduce heating time. The procedure of the modified TS-SIMA process is shown in Figure 1b.
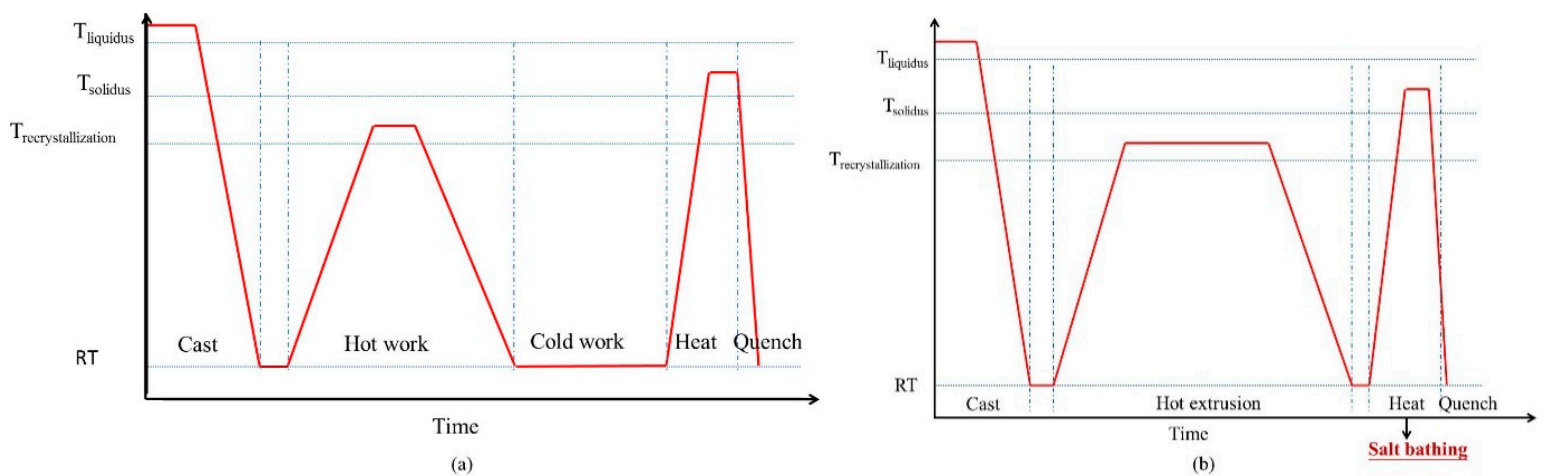

Figure 1. Procedures of (a) traditional three-step strain-induced melt activation (SIMA) process and (b) modified two-step SIMA process. RT: room temperature.

The aims of this research are to determine the effect of TS-SIMA process conditions on microstructural evolution, discuss the formation mechanism of globular grains in the TS-SIMA process, and confirm that the TS-SIMA process can improve the high-temperature compressibility.

\section{Materials and Methods}

The material used in this study was extruded $6066 \mathrm{Al}$ alloy supplied from cooperative aluminum cooperation. Its composition, determined using a glow discharge spectrometer, is shown in Table 1. Two thicknesses ( 3 and $9 \mathrm{~mm}$ ) were selected to determine the effect of strain energy induced by hot extrusion. The 6 in diameter casting materials were extruded with two dimensions of $52 \mathrm{~mm}$ (width) $\times 3 \mathrm{~mm}$ (thickness) and $75 \mathrm{~mm}$ (width) $\times 9 \mathrm{~mm}$ (thickness), respectively. The extrusion ratios of two materials with thicknesses of 3 and $9 \mathrm{~mm}$ (abbreviated as Ex3 and Ex9) were 117:1 and 27:1 (the true strains were 4.8 and 3.3), respectively. Two materials are designated as Ex3 and Ex9.

Table 1. Composition of 6066 aluminum alloy.

\begin{tabular}{cccccccc}
\hline Element & $\mathbf{M g}$ & $\mathbf{S i}$ & $\mathbf{C u}$ & $\mathbf{M n}$ & $\mathbf{F e}$ & $\mathbf{C r}$ & Al \\
\hline Mass $\%$ & 1.02 & 1.29 & 0.98 & 1.02 & 0.19 & 0.18 & Balanced \\
\hline
\end{tabular}

The first phase transformation temperature of $6066 \mathrm{Al}$ alloy was about $565{ }^{\circ} \mathrm{C}$, as shown in Figure 2, which is measured by a differential scanning calorimeter (DSC). In order to determine the effects of salt bath temperature, salt bath duration, and stored strain energy on the microstructure evolution, specimens with two thicknesses ( 3 and $9 \mathrm{~mm}$ ) were heated at $550-630{ }^{\circ} \mathrm{C}$ within $1-60 \mathrm{~min}$ in salt bath. The codes of salt bath specimens with two thicknesses are interpreted by the following example: SB3/620-10 means a material which is $3 \mathrm{~mm}$ in thickness was heated by salt bath at $620^{\circ} \mathrm{C}$ for $10 \mathrm{~min}$.

Microstructural characteristics and grain size were analyzed using an optical microscope (OM) (BX41M-LED, Olympus, Tokyo, Japan). The identification of phases and distribution of elements were detected using an electron probe micro-analyzer (EPMA) (JEOL, Peabody, MA, USA). The liquid fraction of lower-melting-point second phases was measured using ImageJ software (National Institetes of Health, Java 1.8.0_60, New York, NY, USA). Two shape parameters, $x$ and $z$, were defined for the 
degree of spheroidization [7]. In Figure $3, a, b, c$, and $A$ represent the major axis, minor axis, perimeter, and area of grain, respectively. According to the definitions $x=(b / a)$ and $z=(4 \pi A) / c^{2}, x$ is the ratio of the minor axis to the major axis and $z$ becomes closer to 1 as the shape becomes more circular. When $x$ and $z$ are closer to 1 , the grains are more equiaxial and the degree of spheroidization is higher.

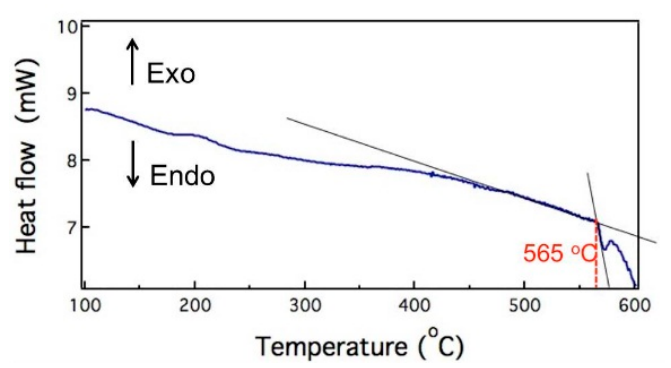

Figure 2. Differential scanning calorimeter (DSC) data of 6066 aluminum alloy. Exo: exothermic; Endo: endothermic.
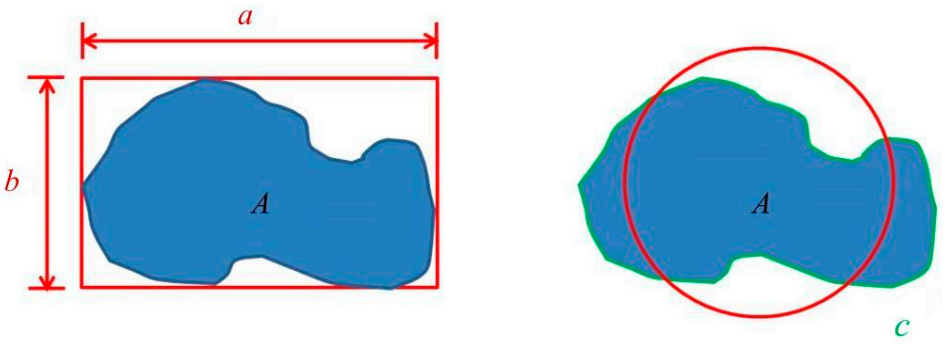

Figure 3. Parameters of spheroidization degree definition. $a, b, c$, and $A$ represent the major axis, minor axis, perimeter, and area of a grain, respectively.

Nine-mm-thick sheets were used in the high-temperature compression tests. As-extruded alloys, fully annealed alloys, and salt bath alloys were tested to compare their high-temperature compressibility. The compression ratio is defined as $R \%=\left(t_{0}-t_{f}\right) / t_{0}$, where $t_{0}$ is the thickness of the initial sheet $(9 \mathrm{~mm})$ and $t_{f}$ is the thickness after compression. The compression temperatures were set as 550 and $600{ }^{\circ} \mathrm{C}$ (abbreviated as C550 or C600). The compression specimens had dimensions of $20 \mathrm{~mm}$ (length) $\times 20 \mathrm{~mm}$ (width) $\times 9 \mathrm{~mm}$ (thickness). The compression rate was $20 \mathrm{~mm} / \mathrm{min}$ and the compressive loading was $60 \mathrm{~kg} / \mathrm{cm}^{2}$. The compression ratios of the above specimens were measured and compared. A higher compression ratio indicates that the resistance of deformation at high temperature is smaller and thus high-temperature formability is better [13]. The compression ratio was calculated and the microstructure of the cross-section parallel to the compression direction was observed.

\section{Results and Discussion}

\subsection{Microstructural Evolution}

Figure 4 shows the microstructure of as-extruded alloys with two thicknesses. A fiber-shape microstructure can be seen in both Figure 6a,b. Additionally, a lot of the second phases are distributed uniformly and a large number of very fine dynamic recrystallized grains appear in the Ex3 alloy as shown in Figure 4a. In contrast, recrystallization only occurred in parts of Ex9, and its recrystallized grain size was larger than that of Ex3, as shown in Figure 4b. The differences between the two materials resulted from the different extrusion ratios. Because the extrusion ratio of Ex3 is higher than that of Ex9, it led the dynamic recrystallization degree of Ex3 to also be higher than that of Ex9. 


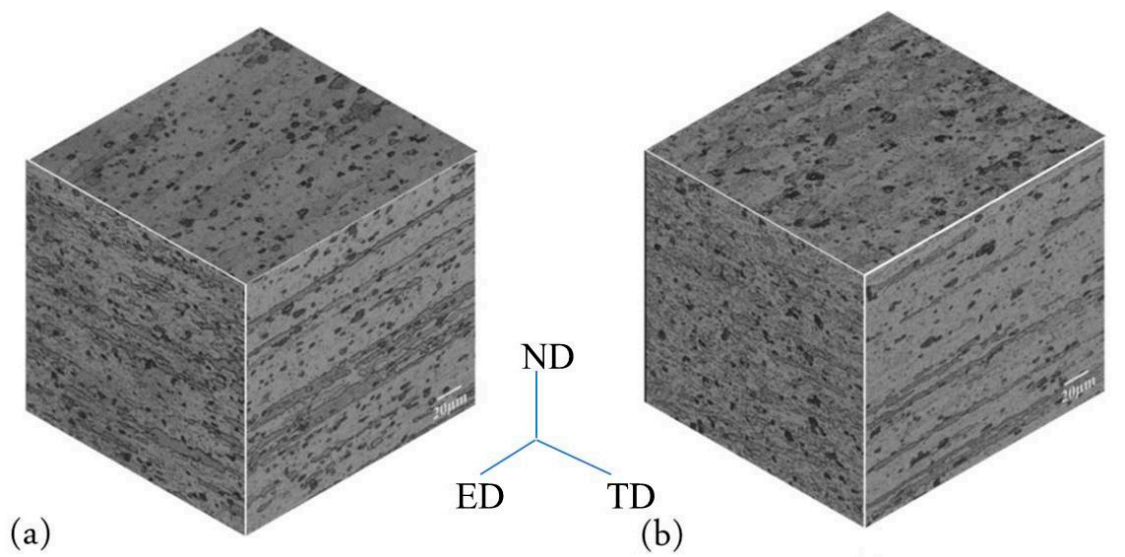

Figure 4. Microstructures of extruded alloys: (a) 3-mm-thickness extruded material (Ex3) and (b) 9-mm-thickness extruded material (Ex9). ED: extruded direction; ND: normal direction; TD: transverse direction.

The effect of salt bath temperatures on microstructure is shown in Figure 5. After a $30 \mathrm{~min}$ salt bath, the grains were not spheroidized uniformly when the temperature was lower than $610^{\circ} \mathrm{C}$, and the material deformed severely or was partially melted severely when the temperature was higher than $630^{\circ} \mathrm{C}$. When the temperature of the salt bath reached $630^{\circ} \mathrm{C}$, melting voids and cracks were probably generated within $7 \mathrm{~min}$ of the salt bath, as shown in Figure $5 \mathrm{f}$.

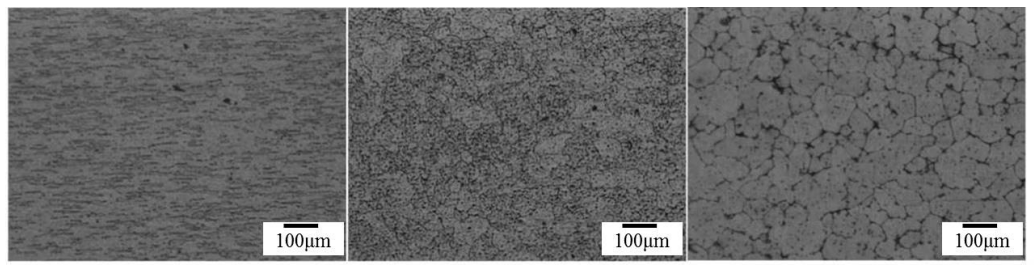

(a)

(b)

(c)

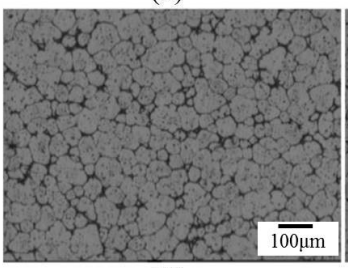

(d)

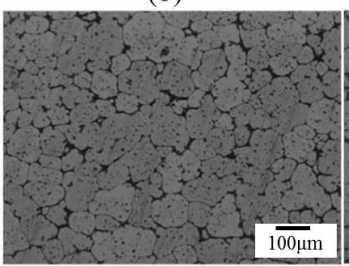

(e)

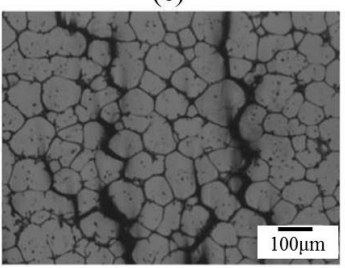

(f)

Figure 5. Microstructure of Ex3 after immersion in salt bath at various time periods (represented by signals in Table 2): (a) SB3/550-30; (b) SB3/570-30; (c) SB3/590-30; (d) SB3/610-30; (e) SB3/620-30; (f) SB3/630-7. SB3: salt bath material with $3 \mathrm{~mm}$ thickness.

Figure 6 shows the microstructure evolution of 6066 alloys in the salt bath at 610,620, and $630^{\circ} \mathrm{C}$ with various time periods. With the increasing salt bath duration, the grain growth increased. For a given duration, a higher salt bath temperature led to higher grain growth except for SB3/610-1 (Figure 7a) and SB3/620-1 (Figure 7d). The average grain sizes of these two specimens are almost identical due to the duration not being long enough for the grain to grow obviously at 610 and $620^{\circ} \mathrm{C}$. The grain growth rates for various salt bath temperatures were calculated based on the Lifshitz-Slyozov-Wagner (LSW) theory $[5,7,14-17]$. The formula is $d^{n}-d_{0}{ }^{n}=K t$, where $d$ is the average grain size that depends on the salt bath duration, $d_{0}$ is the initial grain size, $t$ is the salt bath duration, $K$ (units: $\mu \mathrm{m}^{3} \cdot \mathrm{min}^{-1}$ ) is the coarsening rate constant, and exponent $n$ is determined by the diffusive mechanism of grain growth. For instance, $n=2$ indicates surface diffusion and $n=3$ indicates volume diffusion. In this study, $n=3$ can be used. The theoretical formula can be rewritten as $d^{3}=K t+d_{0}{ }^{3}$, 
which is plotted in Figure 7a. The results of linear fitting are shown in Table 2. The coefficients of determination $\left(R^{2}\right)$ are above 0.98 , indicating that the three results were highly linear. The slopes of the three fitting lines represent the $K$ value (i.e., grain coarsening rate). The $K$ value at $630{ }^{\circ} \mathrm{C}$ was much higher than those at the other two temperatures. The results show that grain growth was very rapid at $630{ }^{\circ} \mathrm{C}$.

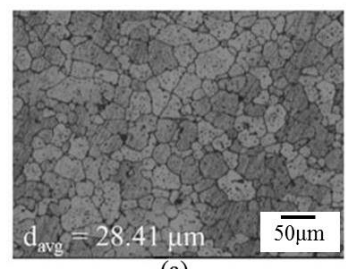

(a)

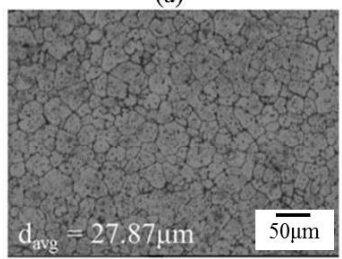

(d)

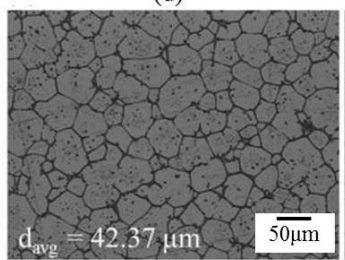

(g)

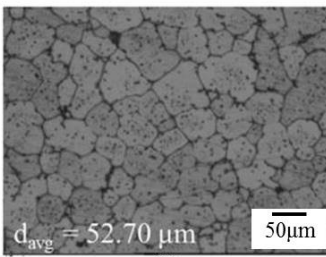

(b)

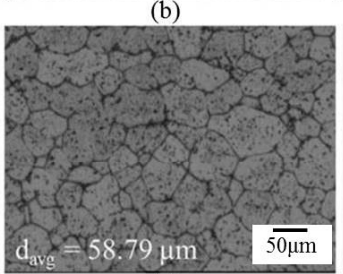

(e)

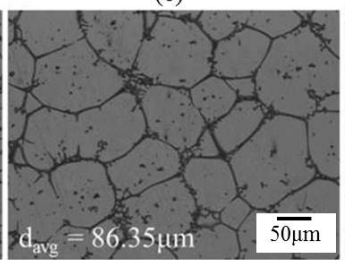

(h)

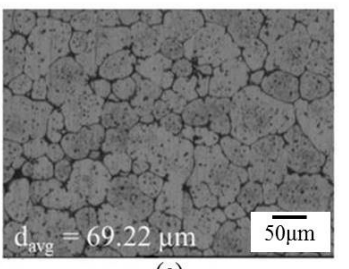

(c)

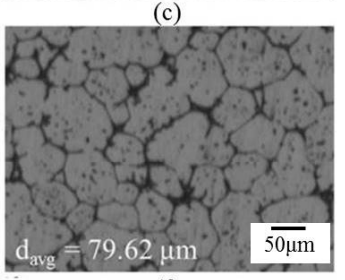

(f)

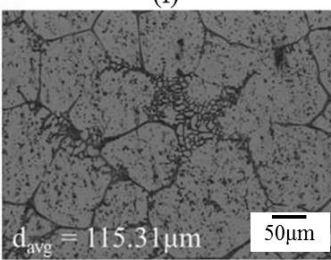

(i)

Figure 6. Microstructures of several materials: (a) SB3/610-1; (b) SB3/610-10; (c) SB3/610-30; (d) SB3/620-1; (e) SB3/620-10; (f) SB3/620-30; (g) SB3/630-1; (h) SB3/630-10; and (i) SB3/630-30.

Table 2. $K$ values and coefficients of determination obtained via linear fitting using Lifshitz-Slyozov-Wagner (LSW) theory for SB3 with various salt bath temperatures. SB3: salt bath material with $3 \mathrm{~mm}$ thickness.

\begin{tabular}{cccc}
\hline Specimen & SB3/610 & SB3/620 & SB3/630 \\
\hline$K\left(\mu \mathrm{m}^{3} \cdot \min ^{-1}\right)$ & 10751 & 16806 & 50820 \\
$R^{2}$ & 0.9852 & 0.9926 & 0.9818 \\
\hline
\end{tabular}

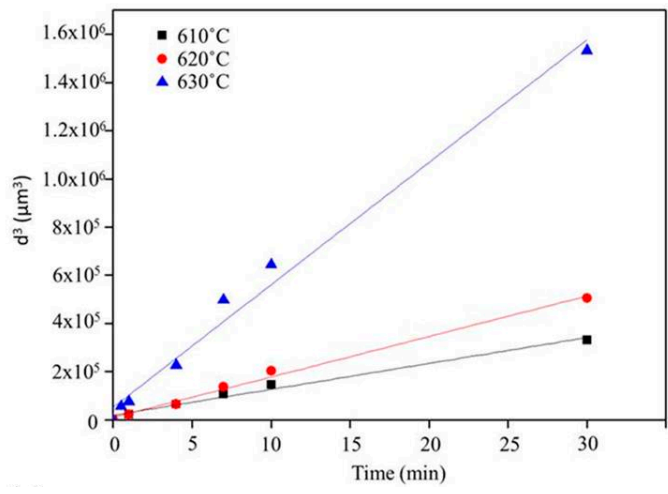

(a)

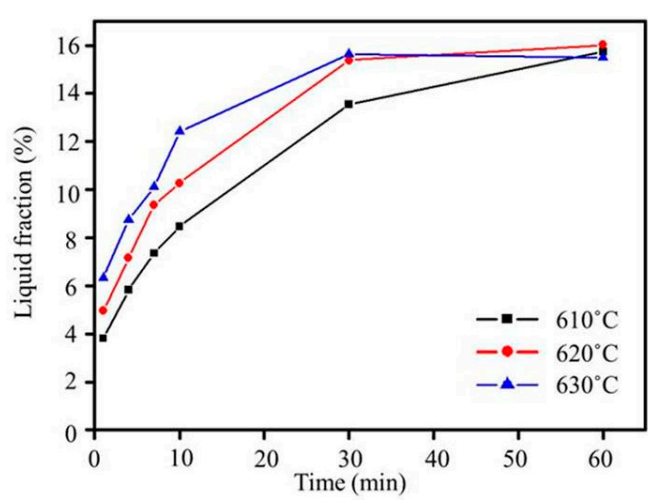

(b)

Figure 7. (a) Plot of grain size versus salt bath duration from Lifshitz-Slyozov-Wagner (LSW) theory (Ex3) and (b) liquid fraction for various salt bath temperatures (Ex3). 
Grain boundary broadening was found for all salt bath temperatures, as shown in Figure 6. This broadening was due to the lower-melting-point second phases melting [18], and the liquid penetrating into the grain boundaries. After quenching, the low-melting-point second phases solidified. When the heating duration of the salt bath was increased, liquid pools formed because large amounts of liquid phases aggregated. The liquid fraction obtained using ImageJ (National Institetes of Health, Java 1.8.0_60, New York, NY, USA) is shown in Figure 7b. The liquid fraction increased with the increasing salt bath temperature and duration. It saturated within $30 \mathrm{~min}$ at the three salt bath temperatures. With the increasing salt bath temperature, the liquid fraction saturation becomes faster. In addition, cracks appeared in the specimen at a salt bath temperature of $630^{\circ} \mathrm{C}$, as shown in Figure $5 \mathrm{f}$, at which the second phases melted and the volume shrank too severely during quenching. The results show that even though $630^{\circ} \mathrm{C}$ was suitable for liquid phase formation, it likely led to the generation of defects. Therefore, $620^{\circ} \mathrm{C}$ was the most suitable salt bath temperature, due to fast liquid formation and high stability.

The influence of the thickness of the extruded alloy was considerable. It represents the effect of strain energy. Figure 8 shows the microstructures of sheets with two thicknesses ( 3 and $9 \mathrm{~mm}$ ). The globular grain size of the SB9 specimen is much larger than that of the SB3 specimen. According to the recrystallization and partial melting mechanism [8,12], the existence of recrystallized grains is necessary for providing high-angle (high-energy) grain boundaries for liquid penetration at high temperatures. In the SB3 specimen, all fine grains were generated all around the material through severe dynamic recrystallization as hot extrusion. In the SB9 specimen, the dynamic recrystallized grains formed only in parts of the material and some static recrystallization occurred within the salt bath period. These dissimilarities resulted in different grain sizes after a given salt bath duration. They also prove that both dynamic recrystallization and static recrystallization provide high-energy grain boundaries for liquid penetration and globular grain formation.

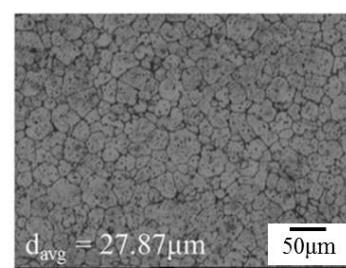

(a)

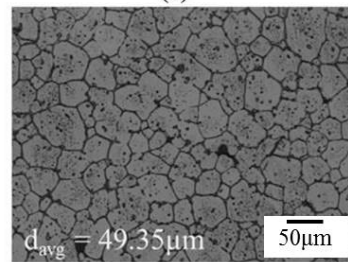

(d)

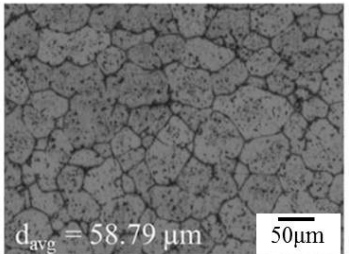

(b)

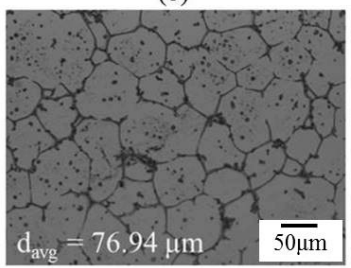

(e)

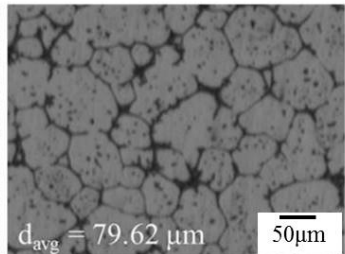

(c)

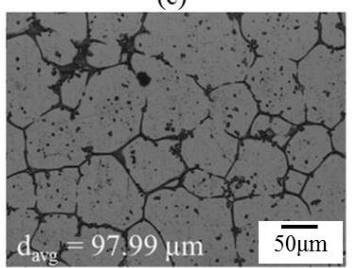

(f)

Figure 8. Microstructures of extruded alloys with two thicknesses after salt bath at $620^{\circ} \mathrm{C}$ : (a) SB3/620-1; (b) SB3/620-10; (c) SB3/620-30; (d) SB9/620-1; (e) SB9/620-10; and (f) SB9/620-30.

For the degree of spheroidization, three representative conditions are plotted in Figure 9. The figure shows that $x$ and $z$ become closer to 1 as the salt bath duration is increased. This indicates that an increase in salt bath duration makes the grains more globular and equiaxial. Increasing the salt bath temperature also improved the degree of spheroidization determined by comparing $z$ values obtained at 610 and $620^{\circ} \mathrm{C}$. The extrusion ratio did not affect the spheroidization determined by comparing SB3 and SB9 at the same salt bath temperature of $620^{\circ} \mathrm{C}$. The results show that the liquid formation enhanced the degree of spheroidization. 


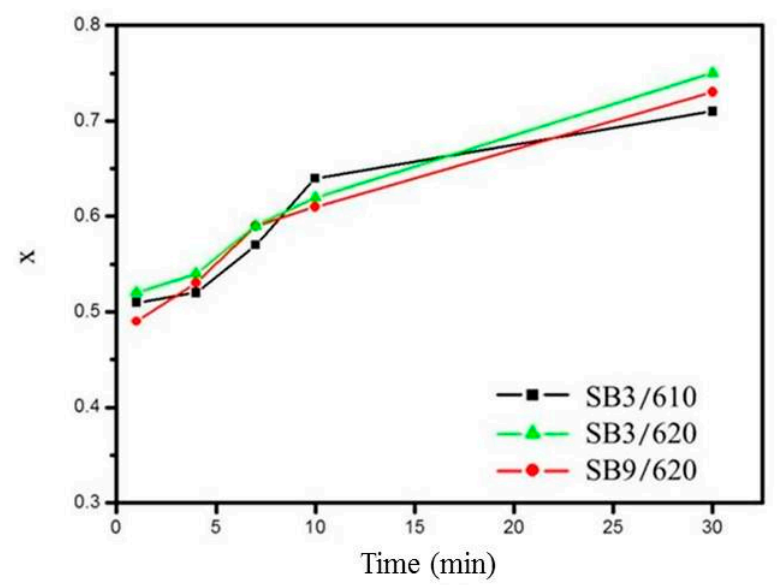

(a)

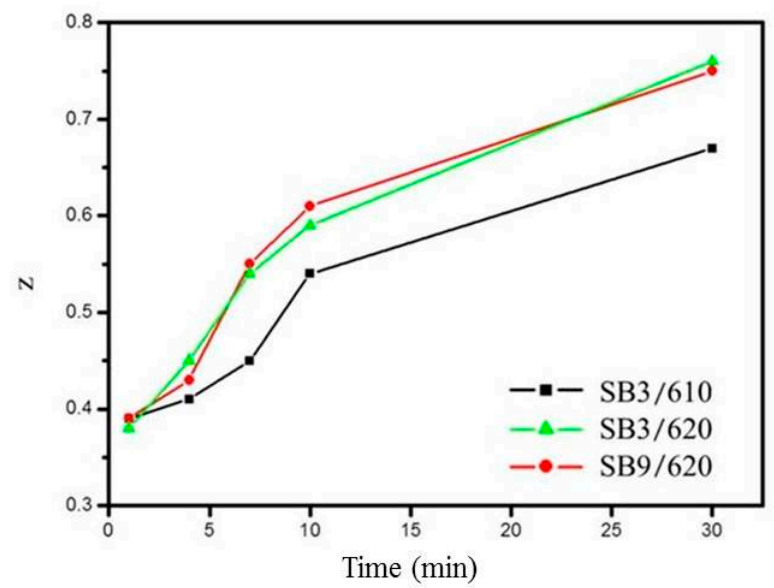

(b)

Figure 9. Variation of degree of spheroidization with salt bath conditions: (a) $x$ and (b) $z$.

The evolution of elemental distribution was analyzed using EPMA. The results are shown in Figure $10 . \mathrm{Mg}, \mathrm{Si}, \mathrm{Cu}$, and $\mathrm{Mn}$, the four major elements added, were distributed uniformly in the as-extruded alloy. After the salt bath, $\mathrm{Mg}$, $\mathrm{Si}$, and $\mathrm{Cu}$ were located at the grain boundaries and formed a network structure, but Mn aggregated as compound particles. This was due to the melting points of Mn-rich phases being higher than $620^{\circ} \mathrm{C}$ [19]. Figure 11 shows the phase analysis using the wavelength-dispersive $\mathrm{X}$-ray spectrometer (WDS) of EPMA. The brighter plate-like grain boundary particles, those marked by " $\mathrm{d}$ ", are mainly composed of $\mathrm{Si}$ and $\mathrm{Cu}$. It is composed of the eutectic phase of $\mathrm{Al}$ and $\mathrm{Al}_{2} \mathrm{Cu}$ and the eutectic phase of $\mathrm{Al}$ and $\mathrm{Si}$. The darker particles marked by " $\mathrm{c}$ " on the grain boundaries and liquid pools are composed of mostly $\mathrm{Si}$ and $\mathrm{Mg}$. It is speculated to be the phase aggregation of $\mathrm{Al}, \mathrm{Mg}_{2} \mathrm{Si}$, and excess $\mathrm{Si}$. Moreover, $\mathrm{Si}, \mathrm{Mn}, \mathrm{Cr}$, and $\mathrm{Fe}$ are the major elements of the brighter equiaxed particles on the grain boundaries and in the grain interior (see those marked by "a"). These particles should be the $\mathrm{Al}_{15}(\mathrm{Fe}, \mathrm{Mn}, \mathrm{Cr})_{3} \mathrm{Si}_{2}$ phase with a melting temperature close to $660^{\circ} \mathrm{C}$. Its particle size increases with increasing the salt bath duration. The coarsening mechanism of the particles probably follows Ostwald ripening, a Gibbs-Thompson effect to reduce the total surface energy. 


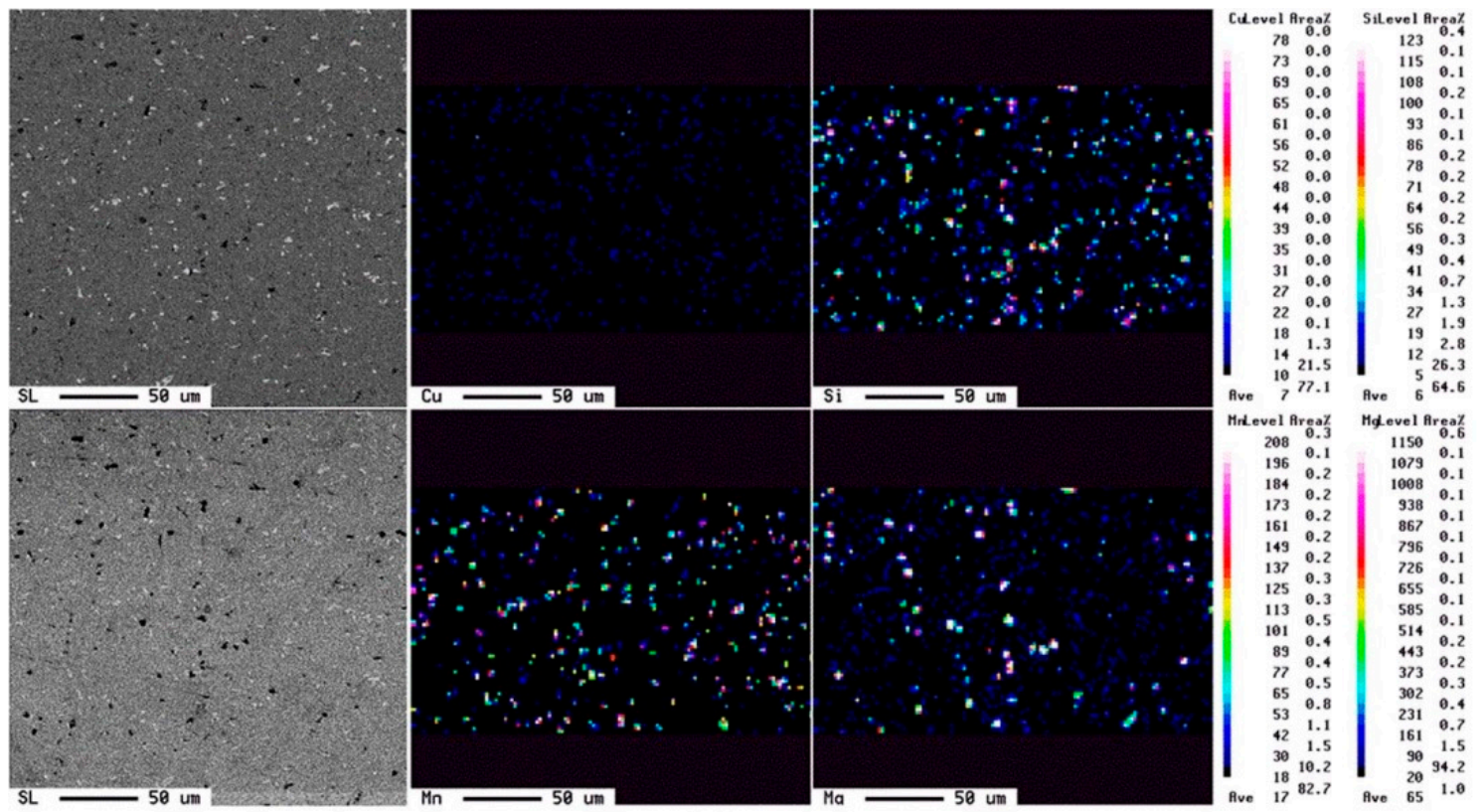

(a)

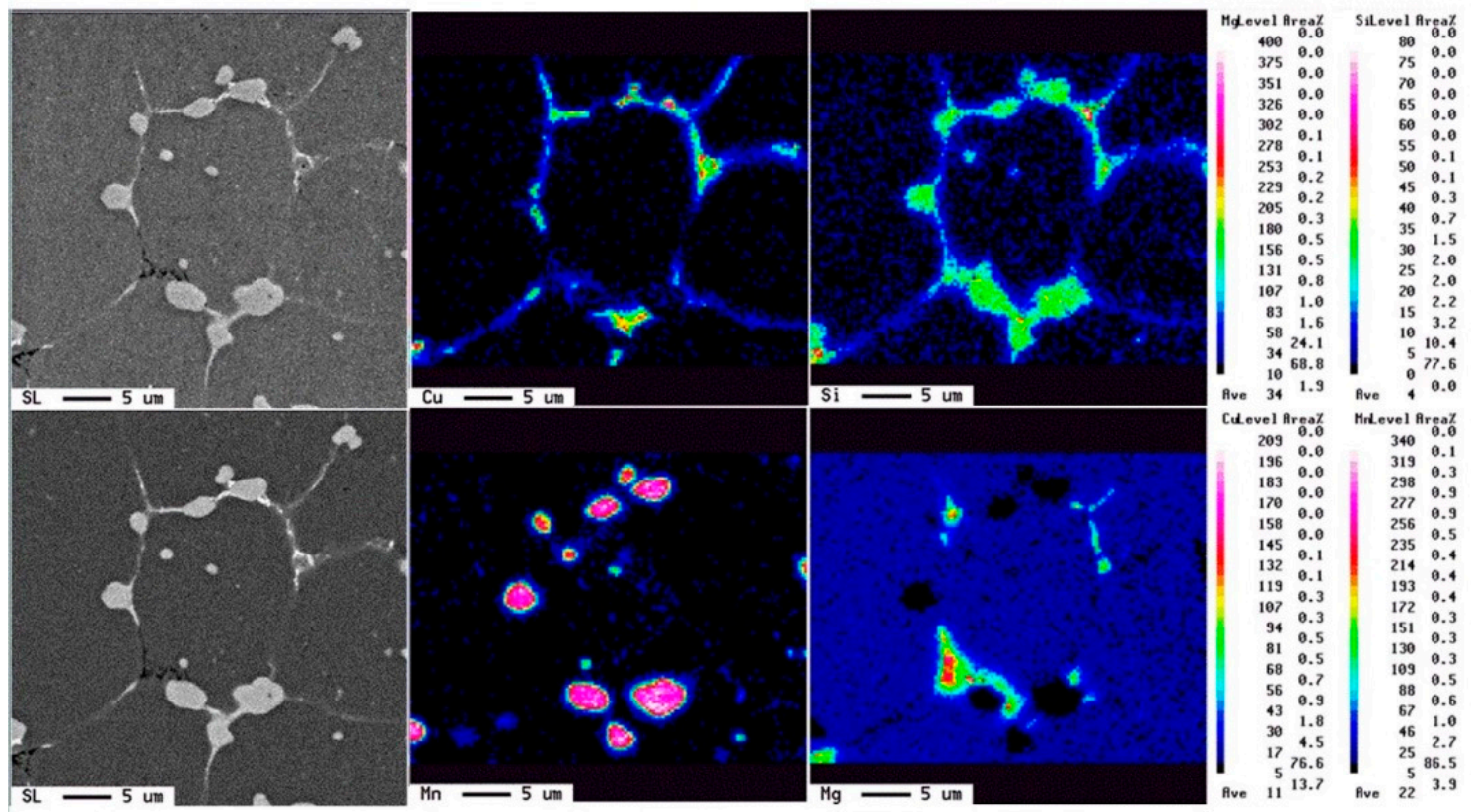

(b)

Figure 10. Elemental distribution obtained using electron probe micro-analyzer (EPMA): (a) Ex3 and (b) SB3/620-1. 


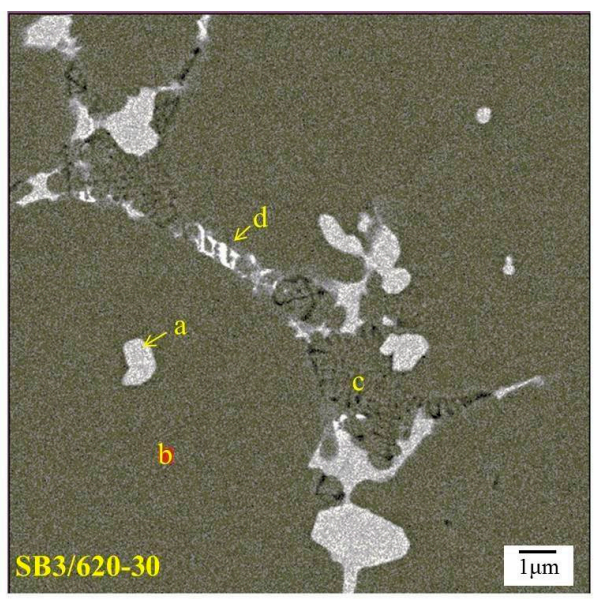

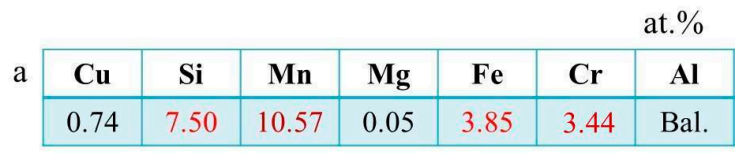

b \begin{tabular}{|c|c|c|c|c|c|c|}
\hline $\mathbf{C u}$ & $\mathbf{S i}$ & $\mathbf{M n}$ & $\mathbf{M g}$ & $\mathbf{F e}$ & $\mathbf{C r}$ & $\mathbf{A l}$ \\
\hline 0.18 & 0.33 & 0.20 & 0.77 & 0.00 & 0.26 & Bal. \\
\hline
\end{tabular}

\begin{tabular}{|c|c|c|c|c|c|c|}
\hline $\mathbf{C u}$ & $\mathbf{S i}$ & $\mathbf{M n}$ & $\mathbf{M g}$ & $\mathbf{F e}$ & $\mathbf{C r}$ & $\mathbf{A l}$ \\
\hline 0.61 & 5.30 & 0.07 & 11.46 & 0.02 & 0.00 & Bal. \\
\hline
\end{tabular}

$\mathrm{d}$\begin{tabular}{|c|c|c|c|c|c|c|}
\hline $\mathbf{C u}$ & $\mathbf{S i}$ & $\mathbf{M n}$ & $\mathbf{M g}$ & $\mathbf{F e}$ & $\mathbf{C r}$ & $\mathbf{A l}$ \\
\hline 10.33 & 16.14 & 0.00 & 1.70 & 0.00 & 0.31 & Bal. \\
\hline
\end{tabular}

Figure 11. Phase analysis of $\mathrm{SB}$. a: $\mathrm{Al}_{15}(\mathrm{Fe}, \mathrm{Mn}, \mathrm{Cr})_{3} \mathrm{Si}_{2}$ particle; $\mathrm{b}$ : $\mathrm{Al}$ matrix; $\mathrm{c}$ dark grain boundary or liqud pool; d: bright grain boundary; red number: major element.

\subsection{Formation Mechanism for the Two-Step Strain-Induced Melt Activation (TS-SIMA) Process}

The mechanisms of globular grain formation for the traditional SIMA process and the TS-SIMA process are shown in Figure 12a,b, respectively. The mechanism of TS-SIMA, shown as Figure 12b, works on the assumption that the grains recrystallize over the whole alloy after hot extrusion (as for Ex3). The procedure for the TS-SIMA process is: (1) a suitable composition alloy is cast with a dendritic microstructure and uniformly distributed secondary phases; (2) the initial dendritic microstructure disintegrates, sufficient strain energy is introduced, and grains are dynamically recrystallized over the material through severe hot extrusion; (3) for the materials subjected to a salt bath, the lower-melting-point second phases melt and the liquid penetrates into grain boundaries and then surrounds the grains; (4) the salt bath makes the grains grow and become globular. Compared to the traditional SIMA process, the proposed TS-SIMA process can produce globular grains faster, and the grains spheroidize uniformly and are finer.

After the salt bath, the microstructure of the Ex9 specimen can also be spheroidized. It indicates that even though the lower stored energy from hot extrusion could not make Ex9 recrystallize fully, the static recrystallized grains in the salt bath also provided high-energy grain boundaries for liquid penetration. In other words, both dynamic and static recrystallization generated grain spheroidization. 


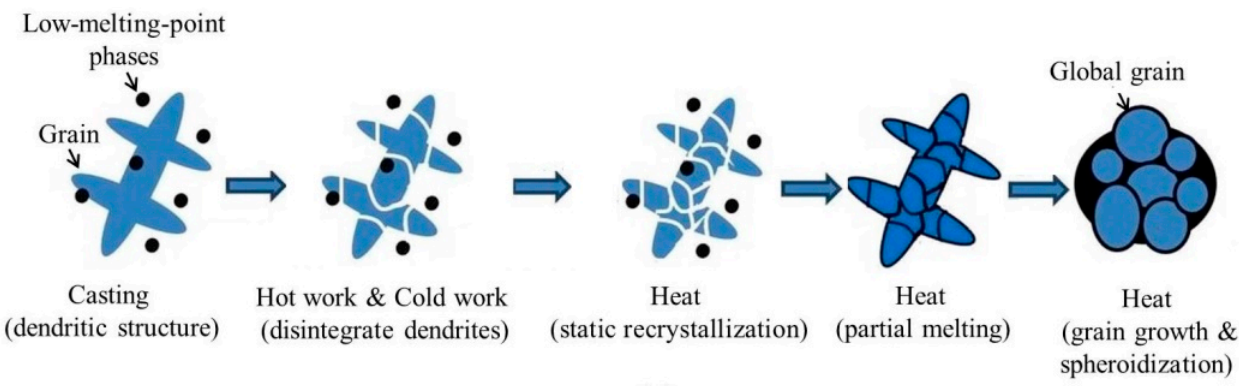

(a)

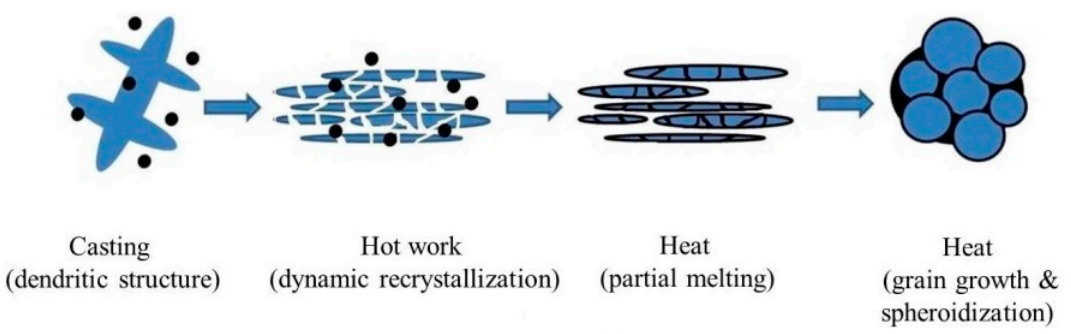

(b)

Figure 12. Evolution of globular grain formation: (a) traditional three-step SIMA process and (b) proposed two-step SIMA process.

For the growth mechanism of globular grains, when alloys are heated to the temperature of solid-liquid coexistence, two coarsening mechanisms are considered [11,20-23], namely grain coalescence and Ostwald ripening. Many studies have indicated that the two mechanisms occur at the same time and do not affect each other. Ostwald ripening dominates for long-duration heating and higher liquid fractions, and grain coalescence dominates for short-duration heating and lower liquid fractions. In this study, the growth mechanism of globular grains followed Ostwald ripening, since the coefficients of determination, shown in Table 2, are very close to 1 for $n=3$ (volume diffusion) in the LSW theory. This theory indicates that as $n$ becomes closer to 3, Ostwald ripening increasingly dominates. Grain coalescence did not dominate majorly because the method of heating was the salt bath, and thus the sample reached the required temperature quickly and the liquid formed almost immediately.

Ostwald ripening is a dissolution-precipitation diffusion-controlled mechanism [9,14]. Large grains become larger and small grains become smaller (even disappearing). As shown in Figure 6, when the salt bath duration and temperature were increased, liquid pools formed. It resulted from small $\mathrm{Al}$ grains dissolving gradually and $\mathrm{Al}$ atoms re-precipitating at neighboring larger grains; therefore, larger grains continued to grow but smaller grains lost $\mathrm{Al}$ atoms until they disappeared. Finally, grain boundaries filled with liquid phases and created liquid pools. Therefore, the appearance of liquid pools is also evidence of Ostwald ripening.

\subsection{High-Temperature Compression of TS-SIMA-Processed Alloy}

For the compression test with a given compression loading, Figure 13 shows microstructures of high-temperature compression samples. The level of grain deformation increased with the increasing compressive temperature. The grains after compression at $600{ }^{\circ} \mathrm{C}$ were flatter than those after compression at $550{ }^{\circ} \mathrm{C}$. Moreover, liquid pools disappeared and grain boundaries became thinner, as shown in Figure 13e (after compression) and Figure 13f (before compression). This phenomenon became more obvious when the salt bath duration was increased. 


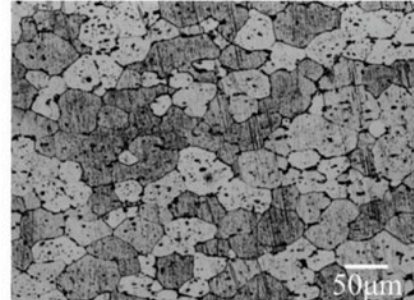

(a)

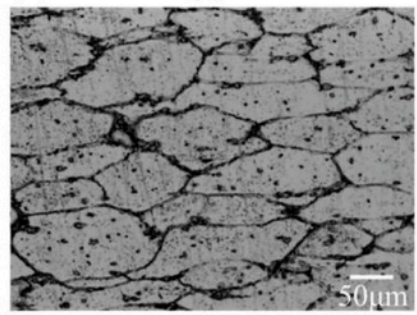

(d)

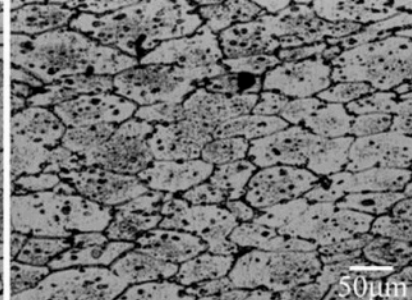

(b)

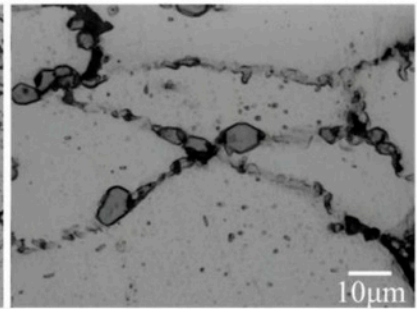

(e)

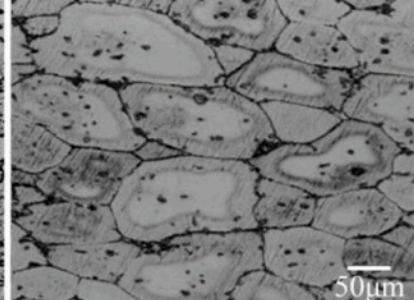

(c)

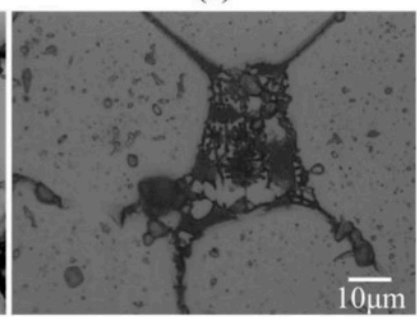

(f)

Figure 13. Microstructural characteristics of grain boundaries before and after high-temperature compression (a) SB9 /620-1 + C550; (b) SB9/620-1 + C600; (c) SB9/620-30 + C550; (d) SB9/620-30 + C600; (e) SB9 /620-30 + C600 (high magnification); and (f) SB9/620-30 (high magnification).

The compression ratios of as-extruded (Ex9), fully annealed (O9), and salt bath samples with various durations (SB9/620-time) are shown in Figure 14. The compression ratio at $600{ }^{\circ} \mathrm{C}$, which is above the solid-liquid coexistence temperature, is much higher than that at $550{ }^{\circ} \mathrm{C}$, which is close to the solid-liquid coexistence temperature. The compression ratio increased with the increasing salt bath duration. The compression ratio of SB9 was higher than that of Ex9 for all salt bath durations and higher than that of $\mathrm{O} 9$ when the salt bath duration was over $4 \mathrm{~min}$. This proves that the high-temperature compressibility can be improved by the TS-SIMA process.

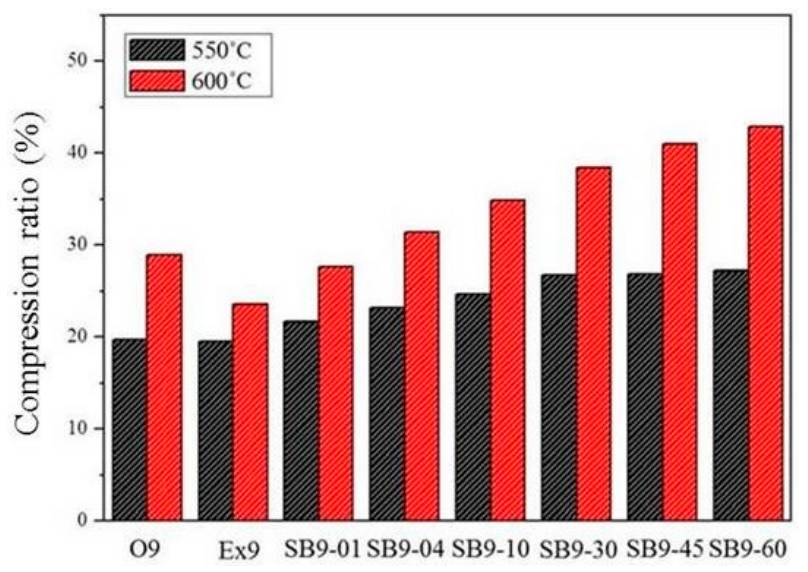

Figure 14. Compression ratios for samples.

The results show that a higher compression temperature (such as $600{ }^{\circ} \mathrm{C}$ ) leads to a higher compression ratio than a lower compression temperature (such as $550{ }^{\circ} \mathrm{C}$ ). Theoretically, the compression ratio is affected by the degree of grain deformation and grain boundary slip due to liquid filling at grain boundaries. The curve of the compression ratio versus salt bath duration, shown in Figure 15, can be divided into two parts: (1) shorter salt bath duration, where the slope of the curve continued to become smaller (resulting from liquid fraction variation, as shown in Figure 7b); (2) longer salt bath duration, where the slope of the curve was almost fixed. In part II, the liquid fraction reaches 
saturation. However, even though the liquid fraction does not increase, grains continue to grow. The grain growth increases the compression ratio according to the Hall-Petch theory [22,23].

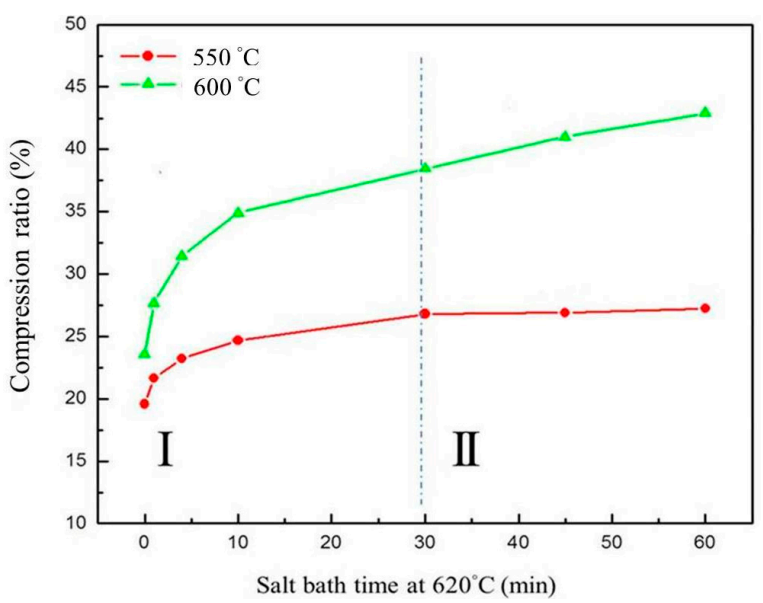

Figure 15. Relationship between compression ratio, salt bath duration, and salt bath temperatures.

\section{Conclusions}

(1) Globular grains were obtained using the TS-SIMA process. The TS-SIMA process has one fewer step compared to the traditional SIMA process, but the degree of spheroidization and uniformity are good. The most suitable salt bath temperature is $620^{\circ} \mathrm{C}$.

(2) Both dynamic recrystallization and static recrystallization provide high-energy grain boundaries for liquid penetration and spheroidized grain formation. The grain growth mechanism of globular grain was Ostwald ripening.

(3) The formation of globular grains increased high-temperature compressibility. After a 4 min salt bath, the high-temperature compressibility of SIMA alloys is higher than that of fully annealed alloys. High-temperature formability can be improved by the TS-SIMA process.

Acknowledgments: The authors are grateful to the Instrument Center of National Cheng Kung University and the National Science Council of Taiwan (NSC MOST103-2221-E-006-056-MY2) for their financial support.

Author Contributions: Chia-Wei Lin, Fei-Yi Hung and Truan-Sheng Lui conceived and designed the experiments; Chia-Wei Lin performed the experiments, analyzed the data and wrote the paper; Fei-Yi Hung, Truan-Sheng Lui and Li-Hui Chen gave suggestions for improving experiments and analysis.

Conflicts of Interest: The authors declare no conflict of interest.

\section{References}

1. Hatch, J.E. Aluminum: Properties and Physical Metallurgy; ASM International: Materials Park, OH, USA, 1984; Volume 1, p. 50.

2. Zhen, L.; Fei, W.D.; Kang, S.B.; Kim, H.W. Precipitation behavior of Al-Mg-Si alloys with high silicon content. J. Mater. Sci. 1997, 32, 1895-1902. [CrossRef]

3. Laughlm, D.E.; Miao, W.F. The effect of $\mathrm{Cu}$ and $\mathrm{Mn}$ content and processing on precipitation hardening behavior in Al-Mg-Si-Cu alloy 6022. Miner. Met. Mater. Soc. 1998, 63-78.

4. Mondolfo, L.F. Aluminum Alloys Structure E Properties; Butterworths: London, UK, 1976; pp. 806-842.

5. Fan, Z. Semisolid metal processing. Int. Mater. Rev. 2002, 47, 49-85. [CrossRef]

6. Song, Y.B.; Park, K.T.; Hong, C.P. Recrystallization behavior of $7175 \mathrm{Al}$ alloy during modified strain-induced melt-activated (SIMA) process. Mater. Trans. 2006, 47, 1250-1256. [CrossRef]

7. Tzimas, E.; Zavaliangos, A. A comparative characterization of near-equiaxed microstructures as produced by spray casting, magnetohydrodynamic casting and the stress induced, melt activated process. Mater. Sci. Eng. A 2000, 289, 217-227. [CrossRef] 
8. Paes, M.; Zoqui, E.J. Semi-solid behavior of new Al-Si-Mg alloys for thixoforming. Mater. Sci. Eng. A 2005, 406, 63-73. [CrossRef]

9. Parshizfard, E.; Shabestari, S.G. An investigation on the microstructural evolution and mechanical properties of A380 aluminum alloy during SIMA process. J. Alloy. Compd. 2011, 509, 9654-9658. [CrossRef]

10. Akhlaghi1, F.; Farhood, A.H.S. Characterization of globular microstructure in NMS processed aluminum A356 alloy: The role of casting size. Adv. Mater. Res. 2011, 264-265, 1868-1877. [CrossRef]

11. Tzimas, E.; Zavaliangos, A. Evolution of near-equiaxed microstructure in the semisolid state. Mater. Sci. Eng. A 2000, 289, 228-240. [CrossRef]

12. Emamy, M.; Razaghian, A.; Karshenas, M. The effect of strain-induced melt activation process on the microstructure and mechanical properties of Ti-refined A6070 Al alloy. Mater. Des. 2013, 46, 824-836. [CrossRef]

13. Lee, K.S.; Kim, S.; Lim, K.R.; Hong, S.H.; Kim, K.B.; Na, Y.S. Crystallization, high temperature defroemtaion behavior and solid-to-dolid formability of a Ti-based bulk metallic glass within supercooled liquid region. J. Alloy. Compd. 2016, 663, 270-278. [CrossRef]

14. Tang, H.; Cheng, Z.; Liu, J.; Ma, X. Preparation of a high strength Al-Cu-Mg alloy by mechanical alloying and press-forming. Mater. Sci. Eng. A 2012, 550, 51-54. [CrossRef]

15. Katayama, T.; Nakamachi, E.; Nakamura, Y.; Ohata, T.; Morishita, Y.; Murase, H. Development of process design system for press forming multi-objective optimization of intermediate die shape in transfer forming. J. Mater. Process. Technol. 2004, 155-156, 1564-1570. [CrossRef]

16. Wang, Z.; Ji, Z.; Hu, M.; Xu, H. Evolution of the semi-solid microstructure of ADC12 alloy in a modified SIMA process. Mater. Charact. 2011, 62, 925-930. [CrossRef]

17. Yan, G.; Zhao, S.; Ma, S.; Shou, H. Microstructural evolution of A356.2 alloy prepared by the SIMA process. Mater. Charact. 2012, 69, 45-51. [CrossRef]

18. Lin, C.W.; Hung, F.Y.; Lui, T.S.; Chen, L.H. High-temperature deformation and forming behavior of two-step SIMA-processed 6066 ally. Mater. Sci. Eng. A 2016, 659, 143-157. [CrossRef]

19. Bolouri, A.; Shahmiri, M.; Kang, C.G. Coarsening of equiaxed microstructure in the semisolid state of aluminum 7075 alloy through SIMA processing. J. Mater. Sci. 2012, 47, 3544-3553. [CrossRef]

20. Hardy, S.C.; Voorhees, P.W. Ostwald ripening in a system with a high volume of coarsening phase. Metall. Trans. A 1988, 19, 2713-2721. [CrossRef]

21. ASM International Alloy Phase Diagram and the Handbook Committees. Alloy Phase Diagram, ASM Handbook 3; ASM International: Materials Park, OH, USA, 1992; pp. 307-308.

22. Zhang, L.; Liu, Y.B.; Cao, Z.Y.; Zhang, Y.F.; Zhang, Q.Q. Effects of isothermal process parameters on the microstructure of semisolid AZ91D alloy produced by SIMA. J. Mater. Process. Technol. 2009, 209, 792-797. [CrossRef]

23. Qin, Q.D.; Zhao, Y.G.; Xiu, K.; Zhou, W.; Liang, Y.H. Microstructure evolution of in situ $\mathrm{Mg}_{2} \mathrm{Si} / \mathrm{Al}-\mathrm{Si}-\mathrm{Cu}$ composite in semisolid remelting processing. Mater. Sci. Eng. A 2005, 407, 196-200. [CrossRef]

(C) 2016 by the authors; licensee MDPI, Basel, Switzerland. This article is an open access article distributed under the terms and conditions of the Creative Commons Attribution (CC-BY) license (http://creativecommons.org/licenses/by/4.0/). 